\title{
El hombre neuronal, treinta años después*
}

\author{
Jean-Piepre Changeux ${ }^{* *}$ \\ DOI: $10.22395 /$ csye.v5n10a9
}

Fue para mí un honor, pero también una seria responsabilidad, participar en este encuentro sobre El hombre neuronal, a la vez como autor y como crítico, un poco más de treinta años después de la publicación del libro. Agradezco muy cordialmente a Michel Morange, Francis Wolff y Frédéric Worms su iniciativa, y a la realización de un programa apasionante que dio lugar a un intercambio de puntos de vista muy constructivos.

\section{Apertura de un debate entre neurociencias y ciencias del hombre}

El título de El hombre neuronal tiene una historia singular. En 1979, el psicoanalista Jacques-Alain Miller, yerno de Jacques Lacan, me invitó a una reunión con sus colaboradores -Jean Bergès, Alain Grosrichard y Éric Laurent- en los locales de la revista Ornicar ${ }^{1}$. Yo estaba solo "en el pozo de los leones", entregado a un fuego de artificio de preguntas sin piedad ni concesión. Salí de allí agotado, pero sano y salvo. Había habido debate, e incluso diálogo eficaz. Frente a mi tenaz determinación, y un tanto inesperada, Miller concluye la discusión proponiendo calificar mi posición de defensa de El hombre neuronal. Sugirió ahí mismo reescribir el Esbozo de una psicología científica que Freud escribió en 1895 sin publicarla por entonces. Si esta reescritura nunca se hizo, sí se había lanzado la señal de un debate informado entre neurociencias y ciencias del hombre y de la sociedad. El hombre neuronal ${ }^{2}$, que exponía de manera sintética los últimos desarrollos de las investigaciones en neurociencias y que estaba directamente inspirado en mis primeros años de enseñanza en el Colegio de Francia, tenía por último objetivo acceder a las funciones superiores del cerebro -lo que se ha convenido en llamar lo "mental"- en términos celulares e incluso moleculares... Sin embargo, yo había tenido ilustres predecesores. Antes

\footnotetext{
Tomado de Michel Morange, Francis Wolff y Frédéric Worms (dirs.). El hombre neuronal, treinta años después. Diálogo con Jean-Pierre Changeux. París: Rue d'Ulm/Presses de l'École normale supérieure, 2016. pp. 121-143. Traducción del francés al español de Luis Alfonso Palau Castaño, Medellín, septiembre 10 de 2016.

** Mis más sinceros agradecimientos a Lydie Duverné-Polilat por la retranscripción de este texto y su trabajo editorial.

1 Jean-Pierre Changeux, "L'homme neuronal, entretiene avec Jean Bergès, Alain Grosrichard, Éric Laurent y Jacques-Alain Miller". Ornicar, 1979, pp. 17-18.

2 Jean-Pierre Changeux (1983). El hombre neuronal. Madrid: Espasa-Calpe, 1985.
} 
incluso de Schopenhauer, los comprometidos por el "juramento fisicalista" de 1845, Brücke, Helmholtz, Du Bois-Reymond (e incluso Freud) proclamaban que "solo existen fuerzas físicas y químicas en el organismo; la única tarea auténticamente científica será descubrir el modo específico o la forma de acción de esas fuerzas físico-químicas", que sigo sintiendo en armonía con ese "juramento fisicalista", pero la cuestión no es esta. En la época, El hombre neuronal suscitó muchísimos comentarios positivos, pero también críticas bastante severas como las del físico marxista François Lurçat, o del psicoanalista André Green. La más grave para mí fue, durante años, una cierta forma de hostilidad o, peor aún, una indiferencia por parte de los representantes de las ciencias humanas, en particular, de los filósofos. Luego de treinta años, las cosas han cambiado claramente. Este coloquio aportó la prueba de una real apertura y ha alcanzado un nivel superior de discusión entre las ciencias del sistema nervioso de hoy y las ciencias del hombre y de la sociedad. No, el fisicalismo no era el enemigo. Muy por el contrario, él implicaba una evolución muy positiva hacia las ciencias sociales, la vida mental y las construcciones culturales. Mi anhelo más ferviente es que esta evolución se prosiga en los años por venir.

\section{Génesis de El hombre neuronal}

El hombre neuronal fue mi primer libro, con todas las imperfecciones que esto podía comportar. Ya había en los terrenos del Instituto Pasteur eminentes predecesores. Jacques Monod había publicado en 1970 El azar y la necesidad, y François Jacob, en el mismo momento, la Lógica del viviente. El envite era mayor. Para existir al lado de ellos necesitaba tener una motivación sólida para atreverme, al mismo tiempo que me situaba en una tradición pasteuriana firmemente establecida. Su propósito, el de la emergencia de la biología molecular, era amplísimo. El mío, más restringido, no era menos ambicioso, aunque centrado en lo que se llamaba desde 1970 "la neurociencia", esa nueva disciplina que resultaba de la fusión de las divisiones tradicionales de las ciencias del cerebro. Reunía anatomía, fisiología, comportamiento o psicología, con la biología molecular, y estaba llamada a proveer una nueva síntesis entre esas disciplinas heteróclitas. Había que encontrar pues un modo de presentación y un estilo de escritura que permitiera acceder a una visión global y, sin embargo, "fisicalista", del cerebro del hombre y de sus funciones superiores, y que integrara sus múltiples niveles de organización, incluido el nivel molecular.

La redacción del manuscrito fue difícil. Yo solo nunca la habría emprendido. Necesitó un año y medio de esfuerzos en paralelo con la continuación de mis investigaciones, y a veces iay! en detrimento del trabajo de laboratorio. En aquella época yo tenía una intensa actividad experimental. La clonación y la secuenciación del receptor de la acetilcolina estaba en la agenda; la competencia 
internacional era muy fuerte. Pasar tiempo escribiendo un libro no me parecía benéfico para mi investigación. Odile Jacob logró convencerme de lo contrario. Un buen día de 1981, de regreso de la Universidad de Harvard donde ella había trabajado sobre la semántica cognitiva en compañía de Roger Brown y Jerry Kagan, ella vino a verme al Instituto Pasteur. Acababa de concretar con las ediciones Fayard un proyecto editorial que había concebido, y cuyo propósito era reunir ciencias básicas y ciencias del hombre. Evocando el éxito de mi enseñanza en el Colegio de Francia desde 1976, me animó muy seriamente a escribir un libro donde yo podría retomar y desarrollar no solamente los descubrimientos recientes hechos en neurociencia sino también mis propias ideas teóricas sobre el cerebro del hombre. No me convenció inmediatamente. El mundo de la neurociencia estaba entonces dominado, como aún lo está desgraciadamente, por una forma de empirismo generalizado. A diferencia de la biología molecular cuyos padres fundadores fueron a menudo físicos para quienes la teoría no solamente era respetada sino requerida, la reflexión teórica era a menudo desterrada de la biología del sistema nervioso. Reinaba la experiencia, teniendo como prima un elogio marcado por la serendipia, elogio que habría entristecido profundamente a Louis Pasteur para el que "el azar solo les sonríe a los espíritus preparados". Pero luego de pensarlo, terminó por seducirme el proyecto de O. Jacob. ¿Por qué no ir a contracorriente y mostrar el interés que una eventual síntesis teórica sobre el cerebro del hombre podría tener en el desarrollo a largo término de nuestra disciplina? Puesto que yo invertía tiempo y energía en escribir mis cursos, ¿por qué no inscribirlos más duraderamente, llevando como mensaje de fondo una rehabilitación del debate teórico en neurociencia? Me dejé pues convencer y no me he arrepentido. Odile Jacob me animó a todo lo largo de ese difícil trabajo de escritura. Se me venían a la cabeza las nueve redacciones que me había impuesto Jacques Monod para mi primera nota a la Academia, cuando yo era su estudiante. Exigía que una nota a la Academia fuera escrita como un soneto en la que cada palabra parecía necesaria al sentido y a la armonía del todo... y iyo sabía que él iba a ser uno de mis primeros lectores! Sin tener plena conciencia de ello, me había embarcado en una extraordinaria aventura editorial.

\section{Un manuscrito darwiniano, a la manepa de Proust}

Si usted va a consultar el manuscrito de El hombre neuronal en la Biblioteca Nacional, constatará que está esencialmente constituido por bandas de papel pegadas las unas enseguida de las otras. Para la época, el ordenador portátil no existía; yo no podía simplemente regresarme en la redacción. Tenía necesidad de reversibilidad. Escribía pues mi texto con lápiz en una hoja de papel. Pero el borrador no era suficiente; yo recortaba con tijeras las frases que me convenían en bandas de algunos centímetros de ancho que ensamblaba luego progresivamente. Curiosamente los manuscritos de Marcel Proust -con propó- 
sitos ciertamente bien diferentes- están constituidos también de fragmentos ensamblados los unos con los otros. Sus pruebas impresas constituyen rompecabezas de papeles recortados donde todo es recuperado y recombinado. Hay un aspecto darwiniano, por variación, selección, amplificación, en el trabajo de escritura... y yo encuentro en este modo de expresión, trazas materiales del proceso creativo, en ciencia como en literatura.

En el curso de este laborioso trabajo de escritura, me preocupaba tanto por el estilo como por el mensaje científico, y trataba de encontrar aquí y allá expresiones singulares para animar el debate. No se trataba en ningún caso de eslóganes o consignas de orden ideológico como pudo ser percibido a veces. Se trataba principalmente para mí de atraer la atención y de sorprender al lector, para evitar que se aburriera como si estuviera leyendo una exposición científica.

Todos los días, hacia las 5 o 6 de la mañana, me dedicaba a la redacción del manuscrito. Al final de la mañana salía del apartamento hacia el Instituto Pasteur a donde asistía al seminario cotidiano; luego trabajaba en mi laboratorio hasta aproximadamente las ocho de la noche. Poner a punto la introducción me tomó casi tres meses. Cada año yo buscaba darle a mi primera clase una resonancia particular, histórica y filosófica, deseando claramente definir de qué se iba a hablar y cómo aquello se iba a insertar en la historia de las ciencias, y especialmente en la del cerebro. Decidí hacer algo parecido en la obra. Esa puesta en marcha me exigió un intenso esfuerzo de síntesis, pero fue igualmente una gran alegría seguir la evolución de lo que se entendía entonces por "órgano del alma", del "Egipto antiguo a la Belle époque". La redacción de los capítulos siguientes fue más simple, de abajo arriba (botton up), del "cerebro en piezas sueltas" a los "objetos mentales"; luego, en el curso de la evolución, del "poder de los genes" y de la "epigénesis" a la "antropogenia". Deseaba, sin embargo, articular entre ellos esos diversos niveles, a la vez, refiriéndome a los datos disponibles en la época y proyectándome constantemente en el porvenir. La terminación del libro exigió más de un año.

\section{El hombre neuronal y la prensa}

Mi libro iba dirigido principalmente a un centenar de personas que seguían, o habían seguido, mi curso. Pero conoció un éxito que ninguno de nosotros se esperaba (alrededor de 200000 ejemplares), y Bernard Pivot contribuyó a ello sin ninguna duda. En el momento de su aparición, él me invitó al plató de Apostrophes y me colocó frente a un cierto Jean Charron que hablaba de los "eones de la relatividad compleja" que, según él, demostraban que Dios estaba en el origen del Universo. Esta suerte de física mística no dejó de crear un contraste con mi manera de ver. Pero cada uno hizo que el tono permaneciera cordial. Yo 
logré hacer pasar el mensaje simple de que el cerebro es el órgano del pensamiento y que nosotros conocemos el mundo -en particular el de la física- por intermedio de nuestro cerebro. No hubo ninguna provocación de mi parte, sino una gran convicción, y la idea se difundió fácilmente en el gran público. Y entre los periodistas que encontré en ese momento, los de la prensa femenina jugaron (para mi sorpresa) un gran papel. Los recortes de prensa que se conservan en los archivos del Instituto Pasteur dan testimonio de ello. Esos periódicos expresaban un verdadero interés por la psicología, el retorno introspectivo, el psicoanálisis... El hombre neuronal contrastaba por una nueva manera de ver radicalmente diferente, pero complementaria de aquella.

La obra cortaba igualmente con lo que se había publicado en la época en la prensa científica internacional. Frédéric Worms formula elegantemente aquí esa visión de una ciencia en progreso presentada en un tono personal. En este sentido, El hombre neuronal era diferente de los libros de neurociencias como los de sir John Eccles o de Eric Kandel ${ }^{3}$. Estos se interesaban en primer lugar en los aspectos "celulares", esencialmente electrofisiológicos, primero por ellos mismos o -en el caso de Kandel- en relación con el comportamiento de aprendizaje de un organismo simple. En sus obras, la dimensión molecular no estaba desarrollada como yo lo deseaba, y sobre todo no aparecía como central para la comprensión de nuestro cerebro. Desde el comienzo, yo deseaba examinar la manera como los niveles de organización anatómicos y funcionales del cerebro están entrelazados tanto de abajo arriba (botton up) como de arriba abajo (top down), y se integran, de manera global, para acceder a las funciones superiores del cerebro del hombre. En aquella época se trataba de un punto de vista bastante personal. Sin duda que estaba ligado a mi recorrido científico singular, que iba de la biología marina a la biología molecular de las bacterias, luego a la extensión de la estrategia de la biología molecular al sistema nervioso y a las ciencias cognitivas. Además, mi estadía posdoctoral en el laboratorio de David Nachmansohn en 1967, en la universidad de Columbia, me había convencido de proseguir mi investigación por la vía bioquímica, distinta de la electrofisiología dominante, y encontrarme (por el juego de las circunstancias y por la filiación de Otto Meyerhof, el maestro de David Nachmansohn) en la tradición de los grandes fisicalistas berlineses, como Duboi-Reymond, Helmholtz, para algunos venidos de los hugonotes franceses perseguidos por Luis XIV.

Otro aspecto personal, y que fue a veces criticado, residía en mi estilo de escritura. A veces se lo consideró denso y pesado, lo que, sin embargo, era deliberado. De manera sistemática yo deseaba articular mis afirmaciones en torno al enunciado preciso de los hechos, la demostración del concepto concernido y la fortuna crítica de él. Había leído la Ética, de Spinoza y, en el subsuelo de mi

3 John Ecless. The physiology of synapses; The self and its brain; Eric Kandell. Cellular basis of behaviour. 
memoria, era un lejano ejemplo por seguir. Había para mí la voluntad de seguir una especie de ética en el modo de comunicación con el público no especializado, de una ciencia que me era querida.

\section{Interdisciplinariedad frente a multidisciplinariedad}

La filosofía general de la obra solo podía ser puesta en operación de manera concreta por un enfoque multidisciplinario. En la época, ese término se confundía a menudo como en la actualidad con el de interdisciplinariedad. La distinción puede parecer anodina, pero no lo es. Estaba al corriente del candente debate que oponía a Jacques Monod y a Louis Althusser que había estado presente en la lección inaugural de Monod en el College de France, y había sido publicada en Le Monde de noviembre de 1967. Althusser gozaba por entonces de un lugar central en la enseñanza de la Filosofía en la Escuela Normal Superior. Había publicado en 1967 una obra que les interesaba a los científicos, y excesivamente olvidada en nuestros días, Filosofía y filosofía espontánea de los científicos. Allí comentaba el uso del término "interdisciplinario" que él presenta, por ejemplo, como una consigna ideológica ilustrada por la práctica de las "mesas redondas" donde se encuentran múltiples participantes administrativos, políticos y "eventualmente" científicos, sin acceder a verdaderos descubrimientos y "que oscilan entre un espiritualismo vago y el positivismo tecnológico". Para Althusser, la interdisciplinariedad es un mito: "Cuando se ignora algo que todo el mundo ignora, es suficiente con reunir a todos los ignorantes; la ciencia saldrá de la reunión de los ignorantes". Numerosos conferencistas utilizan aún este término, sin duda por descuido, porque olvidan la crítica de Althusser. Pero esta parece más que nunca de actualidad. Pienso por ejemplo en algunas prácticas utópicas de la educación escolar. Se lee que "la interdisciplinariedad es la fórmula que permitiría salir del callejón de la especialización del saber a la que ha conducido el desarrollo de la ciencia"4.

También está de moda en los "data-based investigations" cuyos autores se ufanan de que los datos sean recogidos sin concepto previo, con la esperanza de que el análisis "interdisciplinario" pueda hacer emerger nuevos conceptos. Olvidemos pues ese término. La biología molecular, por ejemplo, no es interdisciplinaria; no es una disciplina emergente a medio camino entre lo molecular y lo celular. Es nueva porque ella es, a la vez, molecular y celular. Lo importante en la multidisciplinariedad es el encuentro -la cooperación- de las disciplinas donde cada participante conserva su excelencia a la vez técnica y conceptual, y progresa produciendo modos de integración y tecnologías inéditas. Estoy pues plenamente de acuerdo con Althusser. Y es con convicción que yo trato de escribir un hombre neuronal que responde a las exigencias ide la multidisciplinariedad!

\footnotetext{
4 Jacques Hamel. "La Pédagogie comme pivot de l'interdisciplinarité".
} 


\section{El ADN del "fenómeno humano"}

Un punto central del proyecto de ese libro era para mí examinar lo que los progresos de la genética molecular podían aportar a la comprensión de los orígenes del cerebro del hombre. Yo había leído El azar y la necesidad y encontrado la posición de Jacques Monod excesivamente innatista. El hombre neuronal me dio la oportunidad de abordar el fenómeno humano bajo un ángulo nuevo, al comparar "la simplicidad aparente" del genoma del Homo sapiens con la formidable complejidad anatómica de su cerebro. En los años 1980, no se conocía el número de genes del hombre o del ratón (se los estimaba entre 20000 y 150 000). Los trabajos de secuenciación del genoma lo evalúan en la actualidad en un número comprendido entre 20000 y 25000 en el hombre y en el ratón, lo que no simplifica la discusión. En el capítulo 6 titulado "El poder de los genes" yo precisaba que el contenido total de ADN por núcleo celular era el mismo, mientras que el número de neuronas pasa de alrededor de 5-6 millones en el ratón a algunos 100 mil millones en el hombre. En el curso de la evolución, "una notable no-linealidad existe entre el contenido en ADN y la complejidad del cerebro". En dos millones de años, se pasó del cerebro del Homo habilis (alrededor 510$750 \mathrm{~cm}^{3}$ ) al del Homo sapiens (alrededor de $1400 \mathrm{~cm}^{3}$ ), cuya anatomía difiere de manera importantísima. El aumento de volumen observado y el cambio de organización se produjeron de manera rápida y se distinguen de la evolución del cerebro entre los primates superiores, relativamente lineal y calma.

Muchas hipótesis se presentaban para abordar esta paradoja de no-linealidad. Una primera respuesta se encontraba al nivel del ADN: "el aforismo "un gen-una enzima' de Beadle y Tatum (1941) de ninguna manera se vuelve 'un gen-una sinápsis'... La respuesta hay que buscarla en la manera como (la complejidad del sistema nervioso central) se construye". En el curso del desarrollo, las dinámicas combinatorias de expresiones génicas, secuenciales, jerárquicas y cruzadas, con reempleos y puestas en común, permitían y permiten todavía dar cuenta de la inmensa diversificación de tipos celulares del cerebro a partir de un stock limitado de genes ${ }^{5}$. Ciertamente, "las grandes líneas de la conectividad de la corteza cerebral, en el mono como en el hombre, se ponen en su lugar antes del nacimiento", y modificaciones singulares del genoma y de los modos de expresión génicos pueden tener consecuencias en cascada sobre la evolución del proceso de hominización. Era una primera respuesta al "ADN del fenómeno humano". En la actualidad, treinta años después, el análisis de las secuencias genómicas completas del chimpancé a Homo sapiens, pasando por el hombre de Neandertal y el de Denisova ${ }^{6}$, como el de las expresiones génicas

\footnotetext{
5 Jacques Monod \& François Jacob. "Teleonomic mechanisms in cellular metabolism, growth and differentiation".

6 Svante Päâbo. Neanderthal man; in Search of lost genomes.
} 
en el curso del desarrollo de la corteza cerebral ${ }^{7}$, han progresado considerablemente, pero comportan todavía muchos enigmas. En particular, ¿qué ha pasado con la paradoja de no-linealidad?

Uno de los rasgos más importantes del desarrollo del cerebro humano, a veces sub-estimado por los genetistas y los biólogos moleculares, es que se prolonga durante quince años luego del nacimiento sin que el número total de neuronas cambie significativamente. El bebé humano nace con un cerebro que pesa cinco veces menos que el del adulto (mientras que apenas es el $40 \%$ en el chimpancé) y más de la mitad de las sinapsis de la corteza cerebral se forman luego del nacimiento. El recién nacido humano debe pues ser tomado a cargo por el entorno inmediatamente, familiar, social, para sobrevivir. Esto significa que la evolución darwiniana seleccionó el genoma de una especie que pasa una buen parte de su vida construyendo su cerebro en un entorno social compatible icon su sobrevivencia!

\section{Epigénesis}

Una proposición esencial de El hombre neuronal era que la paradoja de la nolinealidad encuentra una solución principal con "la epigénesis" (el título del capítulo 7). Esta se produce en el curso del desarrollo que sigue al nacimiento, si se puede decir: al ADN constante. El fenómeno está asociado a un nivel superior de organización ausente de todos los otros tejidos del organismo. La célula nerviosa, con sus múltiples arborizaciones axonales y dendríticas, no posee sino un núcleo que no se divide y persiste a todo lo largo de la vida. Una nueva combinatoria se añade a la "tarjeta de identidad" de los genes expresados por la neurona, la de la topología de las conexiones que se establecen entre neuronas en el curso del desarrollo. "Ella no hace intervenir modificaciones del material genético", es epigenética. El modelo sugerido, el de la estabilización selectiva de las sinápsis ${ }^{8}$, propone que el desarrollo de las conexiones está, ciertamente, limitado por una envoltura genética propia de la especie, que incluye la excepcional duración del desarrollo posnatal, pero que preserva en su seno un margen importante de variabilidad, de aleatoriedad. Esta se manifiesta en momentos del establecimiento de las conexiones, por medio de una exuberancia transitoria de las terminales nerviosas exploradoras, que supera en número la conectividad de la red adulta. Se lleva a cabo una selección en la que el estado de actividad del cerebro, espontánea y/o evocada, por la interacción con el entorno, controla la estabilización de algunas conexiones y elimina las otras, y esto en el curso de las múltiples etapas "críticas" encajadas, de la evolución

7 Igor Tsigelny et al., "a Hierarchical coherente-gene-group model for brain development".

8 Jean-Pierre Changeux et al., "a Theory of the epigenesis of neuronal networks by selective stabilization of synapses" 
posnatal. Esta evolución se produce a un ritmo extremadamente rápido puesto que se estima, en promedio, en algunos diez millones el número de sinápsis que se forman por segundo en la corteza del bebé ${ }^{9}$. Y acá un punto esencial: esta selección "darwiniana" está bajo el control de la actividad espontánea y/o evocada de la red. En otros términos "aprender" es eliminar. Como lo sugería ya Lev Vygotsky, el entorno físico, social y cultural del recién nacido se internaliza en su cerebro desde el nacimiento, y quizá incluso antes ${ }^{10}$. Numerosos hechos anatómicos, fisiológicos y comportamentales han apoyado posteriormente la validez del modelo. Entre genes y epigénesis, el cerebro del pequeño Homo sapiens, consciente, racional y social, se vuelve el de una persona capaz y responsable. El "fenómeno humano" obtiene, más allá del ADN, una parte importante de sus orígenes en la epigénesis posnatal.

\section{Filosofía de la impronta cultural}

Un punto importante de la formulación matemática del modelo de la estabilización selectiva de las sinapsis ${ }^{11}$ es el teorema de variabilidad. A la diversidad genética de las disposiciones cerebrales que pueden existir entre individuos en las poblaciones humanas, se superpone una importante variabilidad epigenética del cerebro humano. El teorema demuestra rigurosamente que, en una red neuronal en desarrollo, el mismo mensaje que entra puede estabilizar al mismo mensaje entrada-salida con organizaciones conexionales diferentes. Los individuos que hablan con el hemisferio derecho no se distinguen, por su lenguaje, de los que hablan con el hemisferio izquierdo. Como lo expongo en El hombre neuronal, "la epigénesis asegura la reproductibilidad de la función, a pesar de las fluctuaciones anatómicas que resultan del modo de construcción de la máquina". El código neurocomportamental no se funda en una correspondencia única, término a término, entre red neuronal y comportamiento. Para retomar la expresión de Edelman ${ }^{12}$, está degenerado. Las consecuencias filosóficas son importantísimas. Por ejemplo, a pesar de la diversidad de lenguas y de la variabilidad de las áreas del lenguaje, la traducción tiene una realidad y los seres humanos se comprenden entre ellos. Deben pues existir bases neuronales para la universalidad del sentido. Intensas investigaciones, a la vez teóricas y expe-

$9 \quad$ Hugo Lagercrantz et al., The Newborn Brain Neuroscience and Clinical Applications.

10 Lev Vygotsky. Mind in Society. The Development of Higher Psychological Processes. Cambridge, MA: Harvard University Press, 1978.

11 Jean-Pierre Changeux et al., art. cit.

12 Gerarld Edelman y Vernon Mountcastle. The Mindful Brain ıla hipótesis principal de Edelman es que "el estado consciente resulta de la señalización de la reentrada de fase que se produce en procesos paralelos que implican asociaciones entre los patrones almacenados y la información sensorial o interna en curso". Este proceso selectivo se produce por el filtrado de los repertorios primarios degenerados de grupos neuronales que se forman durante la embriogénesis y el desarrollo. https://mitpress.mit.edu/books/mindful-brain). 
rimentales, están actualmente en curso sobre el fascinante tema de las bases neuronales de las invariantes perceptuales y conceptuales ${ }^{13}$.

Otra consecuencia esencial de la teoría de la epigénesis es que las representaciones producidas por el cerebro de un individuo pueden ser no solamente almacenadas en su cerebro sino que pueden propagarse en el nivel del grupo social y transmitirse de una generación a otra, sin ninguna modificación necesaria del ADN. Una tradición cultural se instala y puede diversificarse, por ejemplo, con el aislamiento geográfico. Puede igualmente enriquecerse de memorias extracerebrales registradas en sustratos más estables que nuestras neuronas y nuestras sinapsis, como la piedra, la madera, el papel, los computadores... La diversidad de las lenguas habladas, incluso la del canto de algunos pájaros, son excelentes ejemplos de ello. Yo mencionaba la escritura al final del capítulo 7. Esta invención humana nació hace alrededor de 6.000 años en Egipto y en Mesopotamia (e independientemente en México), y quizás ya estaban presentes rudimentos de ella hace 40000 años en el arte rupestre. Leer y escribir es algo que vuelve y se aprende hacia los 5 años. La proliferación conexional y sináptica en la corteza cerebral del niño de esa edad es suficiente para que la impronta epigenética de la escritura se inscriba en la conectividad cerebral por medio de un procedimiento estándar de apropiación selectiva de sinapsis. Desde comienzos del siglo XX, el neurólogo francés Jules Déjerine demostraba por medio del análisis de lesiones cerebrales la existencia de circuitos culturales para la lectura y para la escritura, lo que ha sido abundantemente documentado luego por la imagenografía cerebral ${ }^{14}$. Sugerí en $E l$ hombre neuronal que los "objetos culturales" que incluían símbolos, costumbres y tradiciones podían dejar tales huellas epigenéticas en el cerebro. Esas trazas ocupan su lugar en el curso de múltiples períodos sensibles del desarrollo cerebral y son poco reversibles. Escribía entonces que ellas tocaban "el dominio fascinante pero aún demasiado poco explorado de los lazos que unen las neurociencias con la antropología social y la etnología", lo que sigue siendo verdad treinta años después, incluso si las cosas han progresado mucho.

Otro capítulo importante de las ciencias del hombre es evidentemente iel de la historia! Esto me recuerda la intervención de nuestro lamentado colega Jean-Pierre Vernant durante un coloquio de la Unión Racionalista en el Colegio de Francia, donde presentó la historia de la razón en la ciudad griega. Me dijo en aquella ocasión: "Cuando te oigo hablar del cerebro, no veo dónde está la histo-

\footnotetext{
13 James Gibson, "Sensory processes and perceptions. A century of psychology as a science"; Edmund Rolls, "Invariant visual object and face recognition: neural and computational bases and model"; David H. Foster, "Color constancy".

14 Alexandre Castro-Caldas et al., "The Illiterate brain. Learning to read and write during childhood influences the functional organization of the adult brain"; Stanilas Dehaene et al., "How learning to read changes the cortical networks for vision and language".
} 
ria. ¿Dónde me sitúo yo ahí dentro?" Yo le respondí: "la historia es producida en el curso de los siglos por las acciones de los hombres, por tanto por su cerebro, su memoria (selectiva) está registrada por el cerebro de los hombres bajo forma de circuitos culturales pero también de artefactos escritos o de objetos de arte más estables que nuestras actividades neuronales; en fin, el historiador escribe la historia siempre con su cerebro y frecuentemente de manera selectiva". No sé si lo convencí. Pero pienso que esto nos debe incitar a proseguir el diálogo entre neurociencias, historiadores, etnólogos y antropólogos.

\section{Los objetos mentales, el estilo proyectivo y la conciencia}

El objeto fundamental de El hombre neuronal era -además de la cuestión de los orígenes- examinar si los progresos recientes de la neurociencia permitían aprehender los procesos mentales en los niveles moleculares y celulares. ¿Incluso eran suficientes? En otros términos, la posición fisicalista ¿es defendible e, incluso, enriquece nuestra comprensión de lo "mental"? Los capítulos 3 y 4 de la obra, intitulados "Espíritus animales" y "Paso al acto", trataban, respectivamente, de los mecanismos elementales de las comunicaciones cerebrales y sobre la "movilización de conjuntos definidos de células nerviosas" al nivel de los que "debe ser buscada la explicación de las condiciones y de los comportamientos". Este paradigma es siempre de actualidad en la neurociencia contemporánea. Las nuevas tecnologías, como la imagenología celular o la optogenética, han documentado abundantemente esta posición. Pero ella ha evolucionado poco en el plano teórico. Los datos experimentales recogidos después de $E l$ hombre neuronal están en pleno acuerdo con lo que yo llamaría un "fisicalismo ordinario".

¿Qué ha sido de los procesos mentales? En El hombre neuronal yo subrayaba que las metáforas del reloj (de Leibniz) o del computador (de Turing) no se aplicaban para nada al cerebro humano. Este se distingue principalmente por una capacidad de auto-organización que tiene que ver con "percepto, imagen de memoria y concepto (que) constituyen formas o estados diversos de unidades materiales de representación mental, que reagrupamos bajo el término general de 'objetos mentales'". El capítulo 5 se titula precisamente "Objetos mentales". Cuando se lo relee treinta años después, me parece que conserva toda su frescura. Reporta numerosos hechos experimentales y trabajos teóricos que validan sus fundamentos neuronales, e incluso moleculares, y que abogan por la idea fuerte de que los objetos mentales son claramente unidades materiales. Más aún, la génesis de esos grafos de neuronas y de sus trazas de memoria se supone que también procede de manera "darwiniana". La hipótesis propuesta es que habría producción de representaciones espontáneas de bosquejos mal arreglados y transitorios, que yo llamaba pre-representaciones, seguida de su selección en el momento de la interacción con los mundos exterior y/o interno. 
Esta metáfora darwiniana desarrollada igualmente por Gerarld Edelman tiene de interesante que extiende al nivel de lo mental un mecanismo físico ya comprobado en niveles biológicos subyacentes.

La otra ventaja importante es la atribución de un rol mayor a la actividad espontánea del cerebro. En El hombre neuronal yo estudio esta forma singular de actividad en detalle en dos ocasiones: en el capítulo 3, en la sección titulada "los osciladores", y en el capítulo 7, en "los sueños del embrión". Luego ella ha sido abundantemente reexaminada y debatida por Marcud Raichle bajo el término de "estado de reposo" (resting state) ${ }^{15}$. En El hombre neuronal le atribuía una función "generadora de hipótesis" -una actividad creadora-que me parecía importante en el plano teórico. Ella sugería un modo de funcionamiento que sacaba al cerebro de ese marco "entrada-salida" de la informática tradicional, en beneficio de un estilo proyectivo, anticipador o predictivo. Este modo de funcionamiento fue descrito numerosas veces posteriormente, sobre la base del modelo formal de las inferencias bayesianas. Esos modelos, a pesar de la severa crítica de Karl Popper ${ }^{16}$, fueron furor en nuestros días, retomando de hecho el esquema darwiniano, sin interesarse, sin embargo, en sus bases neuronales ${ }^{17}$. Por tanto, nada de neurobiológicamente nuevo con los modelos bayesianos.

El capítulo 5 de El hombre neuronal concluye en una reflexión sobre la "conciencia" que es definida de entrada como "un sistema de regulación global que trata de los objetos mentales y sobre sus cálculos". Ese capítulo retoma los trabajos clásicos de Moruzzi, Magoun y Jouvet sobre el "devenir consciente", la vigilia (y el sueño), subrayando la importancia de la formación reticulada ascendente del tronco cerebral y su extraordinaria diversidad bioquímica. Menciona la importancia del "despertar de la corteza" en las formaciones de perceptos conscientes y el control por la atención "a las operaciones efectuadas sobre los objetos mentales, a su encadenamiento, y por supuesto, a su intercambio con el entorno". Anticipándome a los trabajos más recientes, la importancia de la corteza frontal y de su relación con el sistema límbico está ya indicada en El hombre neuronal. En este contexto, yo presentaba los primeros trabajos de imagenografía cerebral -de ideografía- cuyo pionero fue indiscutiblemente David Ingvar (bien olvidado en la actualidad $)^{18}$. Este ilustraba su aplicación a la patología mental demostrando para ello su hipofrontalidad del "paisaje cerebral" en el esquizo-

15 Debra A. Gusnard \& Marcus E. Raichle, "Searching for a baseline: functional Imaging and the resting human brain".

16 Karl Popper (1938). La lógica de la investigación científica. Madrid: Tecnos, 1962.

17 John Campbell, "Bayesian methods and universal Darwinism"

18 David Ingvar, "Functional landscapes in the brain studied with regional blood flow measurements"; Monte S. Buchsbaum et al., "Cerebral glicography with position tomography. Use in normal subjects and in patients with schizophrenia". 
frénico ${ }^{19}$. Con el boceto de una teoría informal de la "consciencia", yo proponía igualmente incluir en el "sistema de vigilancia" -de "pilotaje"- consciente, las vías de entrada en regreso, de re-aferencia, asignadas inicialmente por Edelman al aprendizaje darwiniano bajo el término de retorno ${ }^{20}$, luego retomado posteriormente en su propia concepción de la conciencia ${ }^{21}$. Yo insistía sobre la idea de que esas neuronas muy divergentes, "esas telas de araña", "funcionan como un todo". Se abría un inmenso campo de investigaciones que condujo a los desarrollos más recientes de las neurociencias cognitivas. Años más tarde (en 1990), Francis Crick y Christof Koch sugerirían que las oscilaciones sincrónicas corticales de $40 \mathrm{~Hz}$ están implicadas de manera causal en la percepción visual consciente. Incluso si la hipótesis fue controvertida, tuvo el poder mediático (de acá en adelante importante en la comunidad científica) de convencer que se podía tener acceso a medidas objetivas de un tratamiento consciente para el cerebro del hombre ${ }^{22}$. Crick avanzó en 1994 con la redacción de un libro titulado The Astonishing Hypothesis que retomaba -"de manera esperada"- la tesis central de $E l$ hombre neuronal.

Entre tanto, los trabajos de anatomía sobre la conectividad cerebral, en particular la RMN de difusión ${ }^{23}$ o tractografía, daban una imagen in vivo de la conectividad a larga distancia de nuestro cerebro. Esto aportaba confirmación a observaciones hechas por Déjerine en los años 1900 sobre disecciones de cerebros humanos post mortem. Es sobre la base de estas observaciones, y de numerosas otras, que el modelo del espacio de trabajo neuronal consciente fue propuesto por S. Dehaene, M. Kerszberg y yo mismo ${ }^{24}$. La idea es que el acceso a la consciencia de un estímulo sensorial, por ejemplo visual, moviliza la red de conexiones a larga distancia que reúne las cortezas pre-frontal, parieto-temporal y cingular (emociones), y se manifiesta por una activación coherente o "ignición" de esa red "global". La neurociencia de los tratamientos conscientes y no conscientes para el cerebro está, de aquí en adelante, reconocida por la comunidad científica y se desarrolla muy activamente ${ }^{25}$.

19 Monte S. Buchsbaum et al., Ibid.

20 Gerarld Edelman y Vernon Mountcastle. The Mindful Brain.

21 Gerarld Edelman y Vernon Mountcastle. Bright air, brilliant fire: on the matter of the mind y a Universe of consciousness: how matter becomes imagination.

22 Stanislas Dehaene y Jean-Pierre Changeux, "Experimental and theoretical approaches to conscious processing".

23 Denis Le Bihan. Le Cerveau de cristal.

24 Stanislas Dehaene, Michel Kerszberg y Jean-Pierre Changeux, "A neuronal model of a global workspace in effortful cognitive tasks".

25 Stanislas Dehaene y Jean-Pierre Changeux, "Experimental and theoretical approaches to conscious processing". 


\section{¿Piensan las bacterias?}

La mayor parte de las moléculas que componen nuestro cerebro son conocidas. Entre ellas, algunos centenares de receptores de neurotransmisores intervienen en la comunicación entre neuronas y, en particular, en el acceso a la consciencia. Esas proteínas estaban ya presentes en El hombre neuronal con el descubrimiento del primer neurotransmisor, el de la acetilcolina ${ }^{26}$. Luego, muchos otros receptores fueron identificados en el cerebro en el nivel molecular, y recientemente se ha llevado a cabo un progreso espectacular en su descripción al nivel atómico. Ya no nos interesamos solamente en un hombre neuronal, sino también en un "hombre atómico". Este último nivel de resolución fue alcanzado con la identificación, en las bacterias, de receptores muy próximos de la acetilcolina de los vertebrados superiores ${ }^{27}$. Por ejemplo, la estructura cristalográfica, en resolución atómica, de un receptor de Gloeobacter -bacteria fotosintética primitiva que vive sobre las rocas calcáreas de los Alpes suizos- es muy próxima de aquella de los receptores de algunos neurotransmisores del cerebro del hombre, como el receptor de GABA o el de la serotonina $5 \mathrm{HT}^{28}$. Poseemos en nuestro cerebro receptores que han sido originalmente seleccionados en las bacterias y que han cambiado muy poco desde hace más de dos mil millones de años. El matemático Alain Connes se sorprendía, en un debate que tuvimos, de que las velocidades de propagación de los signos en el cerebro humano fueron tan lentas, inferiores a la velocidad del sonido, mientras que nuestros computadores funcionan a la velocidad de la luz ${ }^{29}$. Yo le replicaba que la respuesta se encuentra en la obligación temporal estricta que impone la dinámica molecular de las proteínas alostéricas utilizadas en la propagación y la transmisión de los signos nerviosos (receptores, canales iónicos...). Este impresionante ejemplo revela que nuestros ancestros bacterianos nos imponen paradójicamente en la actualidad los tiempos psicológicos de nuestro cerebro. Pero en aquella época ilas bacterias no pensaban todavía!

\section{Sobre los nuevos medicamentos para el cerebro; una responsabilidad ética importante}

Los avances de la investigación en neurociencia no tienen solamente un interés "intelectual"; tienen también consecuencias prácticas importantes sobre la comprensión de las enfermedades neurológicas y psiquiátricas, y el desarrollo

\footnotetext{
26 Jean-Pierre Changeux, Michiki Kasai y Chen-Yuan Lee, "Use a snake venom toxin to characterize the colinergic receptor protein".

27 Jean-Pierre Corringer et al., "Structure and pharmacology of pentameric receptor channels: from bacteria to brain".

28 Ver Marco Cecchini y Jean-Pierre Changeux, "The Nicotinic acetylcholine receptor and its prokariotic homologues: structure, conformational transition and allosteric modulation".

29 Jean-Pierre Changeux y Alain Connes. Materia de reflexión. Barcelona: Tusquets, 1993.
} 
de nuevos medicamentos. Estas enfermedades presentan una apuesta financiera enorme. Su costo para la salud pública era del orden de 798 mil millones de euros para el año $2010^{30}$. Esta considerable suma va a aumentar en los años venideros con la prolongación de la duración de vida. Desafortunadamente, las sociedades farmacéuticas se interesan cada vez menos en el desarrollo de agentes activos sobre el cerebro en razón de los efectos secundarios y del costo exorbitante de los ensayos clínicos. La primera prioridad ética de la investigación en neurociencia es, a mi manera de ver, la concepción de nuevos medicamentos y de tratamientos necesarios para luchar contra el envejecimiento cerebral y las enfermedades degenerativas (del tipo Alzheimer o Parkinson).

Para gran fortuna, la aplicación del mecanismo alostérico a los receptores de los neurotransmisores tiene un impacto significativo sobre la evolución de la farmacología. Se tiene ahora la idea de concebir nuevos medicamentos que puedan actuar sobre sitios que ya no son los de los neurotransmisores o del canal iónico, sino sitios moduladores distintos, identificables por los métodos de cristalografía mencionados antes ${ }^{31}$. Esta concepción "atómica" de la neurofarmacología ofrece de ahora en adelante múltiples posibilidades para la concepción racional de medicamentos...

Esto hace parte de un sector importante de la reflexión en neurociencia: la de las consecuencias éticas que esos trabajos pueden tener para la sociedad futura. Las discusiones en curso sobre este tema en el marco del Human Brain Program (HBP) europeo están aún en gestación. Pero los efectos esperados son considerables. Por ejemplo, en los EE. UU., el financiamiento de los proyectos de investigación del Brain Initiative (el homólogo del HBP) está en parte a cargo del ejército estadounidense: la Defense Advanced Research Proyects Agency (DARPA) financia alrededor del 30\% de los créditos de investigación del Brain Initiative. Al contrario, la sección ética de HBP ha decidido que no era deseable que sus miembros pudieran recibir créditos militares, ni que sus resultados pudieran ser directamente utilizados para fines militares. Es un tema extremadamente sensible que exige un debate abierto y documentado. Estamos en presencia de un tema de reflexión entre muchos otros sobre las consecuencias éticas de los progresos de la neurociencia y de la neuro-informática... ${ }^{32}$.

30 H. Wittchen et al., "The Size and burden of mental disorders and other disorders of the brain in Europe 2010".

31 Ver Marco Cecchini y Jean-Pierre Changeux, ibid.

32 (Para los interesados en la ampliación de este tema por parte de Changeux, cfr. mi traducción J.-P. Changeux, "Punto de vista de un neurobiólogo sobre los fundamentos de la ética", Commentaire \#71. Otoño de 1995. Publicada en la revista Sociología 21, Medellín: Unaula, julio de 1998. Para la recepción del pensamiento de Changeux en nuestro medio: Luis Alfonso Paláu, "Neurobiología y Filosofía", artículo publicado en la revista Sociología 23 de la Universidad Autónoma Latinoamericana, Medellín, marzo de 2000.1 


\section{La descendencia del hombre neuronal: lo verdadero, lo bello, el bien...}

Luego de la publicación de El hombre neuronal, quise proseguir los intercambios entre ciencias del hombre y neurociencia, siempre en el marco de mi enseñanza en el Colegio de Francia, y con los alientos fieles de Odile Jacob. Yo tenía en la cabeza una referencia clásica, la de la axiología platónica ilustrada por sus tres valores principales, lo Verdadero, lo Bello y el Bien. En 1853, ya habían sido objeto de un libro bastante exitoso, de Victor Cousin, pero en un contexto espiritualista. Retomé el título colocándole un subtítulo: "un nuevo enfoque neuronal" que orientaba radicalmente su sentido. La obra resumía de manera sintética mis treinta años de enseñanza en el Collège de France ${ }^{33}$.

Con Materia de reflexión, en 1989, luego El hombre de verdad ${ }^{34}$, en 2002, yo recuperé la cuestión epistemológica fundamental de los procesos de validación - de la puesta a prueba de lo verdadero- en particular en el caso de las matemáticas. De ello concluí que nuestra aproximación a la realidad del mundo exterior implicaba el uso de representaciones cerebrales (matemáticas u otras) que uno proyecta sobre el mundo y de las que no se puede esperar que ellas lo agoten. "La verdad está en el abismo" escribía ya Demócrito.

La naturaleza y la norma ${ }^{35}$ (en 1998) fue la retranscripción de un diálogo, bastante vivo, con el filósofo Paul Ricoeur donde debatíamos sobre los alcances de la ética, tema sobre el que, de manera inesperada, nos entendíamos mientras que, paradójicamente, divergíamos sobre la manera de comprender el cerebro.

Finalmente en Razón y placer ${ }^{36}$ (en 1987) y Las neuronas encantadas ${ }^{37}$ (2014), un diálogo con Pierre Boulez y Philippe Manoury, me interesé en la creación artística, tema de actualidad y que me apasiona siempre.

33 Jean-Pierre Changeux. Sobre lo verdadero, lo bello y el bien. Un nuevo enfoque neuronal. Buenos Aires: Katz, 2011. «Resultado de treinta años de investigación y de enseñanza, síntesis de los conocimientos de las neurociencias y de su desarrollo hasta hoy, es también un libro sobre la cultura y el arte, la vida en sociedad, la ética y la significación de la muerte, así como sobre las lenguas, la escritura y las bases neuronales de la memoria y del aprendizaje. Con la intención de presentar un nuevo enfoque -un enfoque neuronal- de problemas tradicionalmente tratados por la filosofía y las ciencias humanas, Jean-Pierre Changeux, uno de los científicos más relevantes de la actualidad, se ocupa en esta obra de la conciencia y de la manera en que ella se manifiesta en la cultura. Oponiéndose a la distinción clásica entre el dominio de la naturaleza -objeto de las ciencias experimentales- y el dominio de la cultura y del espíritu -objeto de las ciencias humanas y de la filosofía-, el autor plantea que ya no es necesario protegerse de la ciencia, pues esta trae consigo tantas enseñanzas filosóficas como la filosofía misma, comenzando por una reelaboración del concepto de libertad, hoy, en definitiva -particularmente en el terreno de la biología molecular-, el verdadero objeto de la ciencia. "Este libro intenta mostrar que es nuestra responsabilidad incitar constantemente el cerebro de los hombres a inventar un futuro que permita a la humanidad acceder a una vida más solidaria y más feliz para cada uno y entre nosotros." J.-P. Changeux).

34 Jean-Pierre Changeux. el Hombre de verdad. México: Fondo de cultura económica, 2005.

35 Changeux y Ricoeur. Lo que nos hace pensar. Madrid: Fondo de cultura económica, 2001.

36 Jean-Pierre Changeux. Razón y placer. Barcelona: Tusquets, 1996.

37 Boulez, Changeux y Manoury. El cerebro y la música. Barcelona: Gedisa, 2016. 
No es útil volver acá sobre cada una de estas obras. Pero me gustaría mencionar, para concluir, un concepto común que tiene que ver con los múltiples aspectos de la participación del cerebro en la interacción social, el de regla epigenética.

La centena de miles de millones de neuronas, y el millón de miles de millones de conexiones sinápticas de nuestro cerebro crean un número de posibilidades combinatorias realmente astronómico. Si el acceso a todas esas combinaciones fuese el mismo en un instante dado, se requerirían milenios para encontrar la buena... En su comunicación con él mismo y con su entorno social, el ser humano se encuentra en realidad confrontado con un número mucho más restringido y pertinente de representaciones cerebrales. El concepto propuesto (en particular en El hombre de verdad) es que el cerebro del hombre posee la capacidad de elaborar "reglas", muy a menudo encajadas, que limitan, de arriba abajo, el número y la naturaleza de las representaciones cerebrales accesibles y que intervienen como una suerte de "marco neuronal adquirido". La hipótesis es que estos conjuntos de neuronas movilizados en el espacio del trabajo neuronal consciente, y almacenados en la memoria a largo términos bajo forma de trazas epigenéticas, definen "reglas" de conducta. En el sujeto consciente, la corteza frontal interviene en el descubrimiento de reglas de acción abstracta de ese tipo, en la búsqueda de relaciones entre contexto y acción ${ }^{38}$.

A mi manera de ver, las matemáticas se componen y se construyen a partir de reglas epigenéticas adquiridas, desde las reglas de la suma y la resta que aprende el niño, hasta las ecuaciones más elaboradas en el cerebro de los matemáticos de la teoría de cuerdas...

A propósito de las reglas del arte, Braque escribe: "amo la regla que corrige la emoción", a lo que responde Boulez: "amo la emoción que corrige la regla". Entre estas reglas del arte, se nota la novedad, la parsimonia (o la economía de medios), el consensus partium (o la armonía de las partes y del todo), el exemplum (el mandamiento ético), la manera de hacer que, por ejemplo en el pintor compromete el toque, el color, la composición... que firman el estilo del artista:

[...] Lo que llamamos la realidad es cierta relación entre esas sensaciones y esos recuerdos que nos circundan simultáneamente [...] relación única que el escritor debe encontrar para encadenar para siempre en su frase los dos términos diferentes [...] la verdad solo empezará en el momento en que el escritor tome dos objetos diferentes, establezca su relación, análoga en el mundo del arte a la que es la relación única de la ley causal en el mundo de la ciencia, y los encierre en los anillos necesarios de un bello estilo ${ }^{39}$.

38 Ver Étienne Koechlin, Chriystèle Ody y Frédérique Kouneiher, “The Architecture of cognitive control in the human prefrontal cortex"; David Badre, Andrew S. Kayser y Mark D'Esposito, "Frontal cortex and the discovery of abstract action rules".

39 Marcel Proust. En busca del tiempo perdido. 7.- el Tiempo recuperado. Librodot.com pp. 122-123. Citado por Marcel Henaff en ¿Violencia en la razón? Conflicto y crueldad. 
Toda reflexión multidisciplinaria sobre la cuestión de las normas éticas tropieza inexorablemente con la proposición de Hume, según la cual "la actividad científica establece lo que es o lo que no es", mientras que "las proposiciones de un sistema moral definen lo que debe o lo que no debe ser hecho" y prescribe las reglas o las normas de conducta. El enfoque que consiste en buscar las bases neuronales de las normas éticas parece ir en contravía de este principio. Pero, según mi saber y entender, él es fiel al pensamiento crítico de Hume que es "encerrar las investigaciones (...) entre los límites de la experiencia". La dificultad de la reflexión ética viene de que los seres humanos son ampliamente autocentrados y autoprotectivos en su vida social. Paul Ricoeur propone en Uno mismo como otro que, por este hecho, cada proyecto-intención sea sometido "al filtro de la norma".

Ese filtro reposa, a la vez, sobre un cierto corpus innato de predisposiciones cerebrales al juicio moral que, a mi manera de ver, constituyen la humanitas (Kant) del cerebro del Homo sapiens y, por supuesto, sobre el entorno constantemente renovado que crea la evolución de las civilizaciones humanas. Por ejemplo, es interesante anotar que la regla de oro "no hagas a los otros lo que no quieres que te hagan a ti" haya aparecido casi simultáneamente y (parece que independientemente) en la China con Confucio (hacia el 500 a. de Xto.), luego en Occidente en el Levítico (hacia el 400 a. de Xto.: "ama a tu prójimo como a ti mismo"). Es decir -y este es un hecho importante para nosotros- en contextos históricos y sociales diferentes, que pueden ser tan ateos como teístas, pero que corresponden según mi opinión, a un nivel de civilización común y a un cerebro común.

En este contexto, muchos colegas bien intencionados han criticado mi visión del hombre exageradamente optimista. Apenas si se ve surgir el "Mal"... Marcel Hénaff, en Violence dans la raison? retoma la paradoja promovida por Konrad Lorenz según la cual el hombre sería un ser particular que el azar de la evolución habría constituido en un estado de desequilibrio considerable: debilidad física, inteligencia excepcional y medios superpotentes de destrucción. Por eso la metáfora propuesta por Lorenz (1987): "el hombre sería como una paloma al que una bufonada de la naturaleza habría dotado de un pico de cuervo". Según una tal configuración, la especie humana sería ella misma rápidamente aniquilada, lo que explicaría que hubieran aparecido las prohibiciones morales. Y no deja de ser cierto que, incluso si la empatía y la simpatía natural existen en el seno de las poblaciones humanas; incluso si la regla de oro apareció hace más de dos mil años, y la Declaración de los derechos del hombre hace más de dos siglos, se ve repetir hoy por ejemplo con Daech (Estado Islámico) en el medio Oriente, la misma insostenible crueldad, la misma barbarie que conoció Europa de manera repetida: en el siglo XVI con las guerras de religión, en el siglo 
XVIII con el Terror, en el siglo XX con el nazismo y la Shoah. Y la paradoja bien documentada en lo concerniente a los nazis es que los oficiales alemanes que, durante el día, dirigían los campos de exterminio, llevaban en la noche una vida familiar y una vida social aparentemente "normal". Para mí esta es una paradoja neuronal, que me parece extremadamente importante comprender y prevenir. En las circunstancias evocadas, un proceso de "deshumanización" está funcionando en el cerebro que confiere instantáneamente al otro un estatuto de no-humano que hay que eliminar sin consideración. Espero que nuestros conocimientos sobre el cerebro nos permitirán avanzar en la comprensión de las estructuras sociales, políticas y económicas que provocan pasos al acto de una tal barbarie.

Una nota de esperanza para terminar. Como lo proponemos Kathinka Evers y yo, iseamos "epigenéticamente proactivos"! 40 Encontremos los medios de hacer de forma que la evolución de nuestras estructuras sociales y económicas, de nuestros sistemas de educación a escala mundial, de nuestras mentalidades, interactúen de manera constructiva y "epigenética" con las arquitecturas neuronales de nuestros cerebros y... que la neurociencia nos haga anticipar, progresar, luchar contra la barbarie, teniendo por último objetivo, como lo pedía Pasteur, el "bien de la humanidad". Es esta nuestra responsabilidad de científico y de filósofo.

40 Ver Kathinka Evers y Jean-Pierre Changeux, "Proactive epigénesis and ethical innovation." 
